\title{
Homeopathic-Spagyric Therapy of Acute and Uncomplicated Rhinosinusitis: An Observational Trial on Symptom Severity in 2 General Practitioner Surgeries
}

\author{
Stefan Schmidt ${ }^{a, b}$ Hans-Joachim Kaestle ${ }^{c} \quad$ Uwe Steinhausen $^{d}$ \\ a Department of Psychosomatic Medicine and Psychotherapy, Faculty of Medicine, Medical Center - University of Freiburg, \\ Freiburg, Germany; \\ b Institute of Transcultural Health Sciences, European University Viadrina, Frankfurt (Oder), Germany; \\ ${ }^{\mathrm{c}}$ General Practice Dr. med. Kaestle, Wangen, Germany; \\ dGeneral Practice Dr. med. Steinhausen, Ravensburg, Germany
}

\section{Keywords}

Homeopathy - Spagyric therapy - Sinusitis .

Observational study

\section{Introduction}

Rhinosinusitis is one of the most frequent reasons to consult a general practitioner (GP) surgery. They often occur as a sequel of a common cold where viruses are known to be the primary cause in more than $90 \%$ of the cases [1]. Thus, rhinosinusitis usually heals completely within 3 weeks at most. For treatment, antibiotics should be restricted to severe and complicated courses [2]; nevertheless, in at least $60 \%$ of the cases, antibiotics are prescribed. In a Cochrane Review, it was shown that only 5 out of 100 patients treated with antibiotics recovered faster while these patients experienced significantly more adverse events than those receiving placebo [3].

With respect to homeopathy, only studies regarding complex remedies have been published. Two randomized controlled studies (RCTs) on 2 different complex remedies reported a significant reduction in symptoms of acute rhinositis compared to placebo $[4,5]$.

Such RCTs can answer questions regarding the efficacy of treatments with high internal validity. However, this comes always at the cost of the external validity since the trial regime (exclusion criteria, randomization, placebo arm) departs decisively from daily routine. Thus, these studies need to be complemented by trials with higher external validity [6]. Observational trials within the context of health service research can fill this gap because they pro-

\author{
Schlüsselwörter \\ Homöopathie · Spagyrik · Rhinosinusitis . \\ Beobachtungsstudie
}

vide high external validity although possessing lower internal validity in return. Such trials are able to supplement the scientific perspective of specific efficacy with a 'patient-centered' perspective regarding overall effectiveness. This mostly neglected perspective of the patient is of major importance since patients usually do not care whether health effects due to medications are specific or unspecific, but are highly interested in the overall effects [7].

The objective of the present trial was to collect data from the daily routine of 2 GP surgeries regarding the question whether acute rhinosinusitis can be treated adequately and sufficiently with a homeopathic-spagyric remedy named RICURA ${ }^{\circledR}$ spag. Peka N regardless of the type of pathogen and without using any antibiotics.

\section{Methods}

Patients suffering from rhinosinusitis who consulted 2 surgeries in southern Germany between November 2012 and April 2013 were offered to participate in the study. We excluded patients with diabetes mellitus, chronic-recurring sinusitis, persistent purulent secretion off paranasal sinus, and low immunity, as well as patients aged below 18 or above 80 years. The study was approved by the ethics commission of the University Medical Center Freiburg.

Primary outcome was the severity of symptoms measured with the Sino-Nasal Outcome Test (SNOT-16) [8, 9], a 16-item patients'

\section{KARGER}

() 2016 S. Karger GmbH, Freiburg 
Table 1. Mean values, test statistics, and effect sizes at t0 (baseline), $\mathrm{t} 1$ ( 3 days), and $\mathrm{t} 2$ (10 days, end of treatment) for the 3 outcome criteria 'symptom severity' (SNOT16), 'c-reactive protein' (CRP), and 'blood sedimentation rate' (BSR) in the first (BSRa) and second hour (BSRb)

\begin{tabular}{|c|c|c|c|c|c|c|c|}
\hline \multirow[t]{2}{*}{ Variable } & \multirow[t]{2}{*}{ to } & \multirow[t]{2}{*}{$\mathrm{t} 1$} & \multirow[t]{2}{*}{$\mathrm{t} 2$} & $\mathrm{t}$-Test & d & \multirow{2}{*}{$\frac{\mathrm{t} \text {-Test }}{\mathrm{t} 0-\mathrm{t} 2}$} & \multirow{2}{*}{$\frac{d}{t 0-t^{2}}$} \\
\hline & & & & $\mathrm{t} 0-\mathrm{t} 1$ & $\mathrm{t} 0-\mathrm{t} 1$ & & \\
\hline SNOT-16 (SD) & $45.4(10.92)$ & $31.4(15.10)$ & $15.7(13.65)$ & $\begin{array}{l}\mathrm{T}=6.203 \\
\mathrm{df}=48 \\
\mathrm{p}<0.001\end{array}$ & 1.08 & $\begin{array}{l}\mathrm{T}=14.194 \\
\mathrm{df}=46 \\
\mathrm{p}<0.001\end{array}$ & 2.42 \\
\hline CRP, mg/l (SD) & $8.8(8.50)$ & $9.2(10.99)$ & $4.6(5.49)$ & $\begin{array}{l}\mathrm{T}=-0.213 \\
\mathrm{df}=45 \\
\mathrm{p}=0.832\end{array}$ & -0.04 & $\begin{array}{l}\mathrm{T}=3.942 \\
\mathrm{df}=41 \\
\mathrm{p}<0.001\end{array}$ & 0.60 \\
\hline $\begin{array}{l}\text { BSRa, mm } \\
\quad \text { after } 1 \mathrm{~h}(\mathrm{SD})\end{array}$ & $13.8(10.89)$ & $14.0(11.45)$ & $9.4(7.16)$ & $\begin{array}{l}\mathrm{T}=-0.123 \\
\mathrm{df}=45 \\
\mathrm{p}=0.90\end{array}$ & -0.02 & $\begin{array}{l}\mathrm{T}=3.750 \\
\mathrm{df}=39 \\
\mathrm{p}<0.001\end{array}$ & 0.49 \\
\hline $\begin{array}{l}\text { BSRb, mm } \\
\quad \text { after } 2 \mathrm{~h} \text { (SD) }\end{array}$ & $26.6(17.34)$ & $27.0(20.15)$ & $17.7(11.38)$ & $\begin{array}{l}\mathrm{T}=-0.163 \\
\mathrm{df}=39 \\
\mathrm{p}=0.87\end{array}$ & -0.02 & $\begin{array}{l}\mathrm{T}=4.769 \\
\mathrm{df}=39 \\
\mathrm{p}<0.001\end{array}$ & 0.62 \\
\hline
\end{tabular}

$\mathrm{SD}=$ standard deviation . questionnaire assessing the general feeling and the course of the disease. As secondary outcomes measures, C-reactive protein (CRP) as well as blood sedimentation rate (BSR) were assessed.

Patients filled in the questionnaires and gave blood samples at baseline ( $\mathrm{t} 0$ ). Measurements were repeated after 3 days $(\mathrm{t} 1)$ and after10 days (end of treatment; t2). The re-occurrence of complaints was assessed 4 weeks after $\mathrm{t} 2$ ( $\mathrm{t} 3$ ).

Patients were treated with the homeopathic-spagyric remedy RICURA ${ }^{\circledR}$ spag. Peka N. It contains Luffa operculata D6, Kreosotum D6, Hydrargyrum sulfuratum rubrum D12, Echinacea spag. Peka D12, Capsicum annuum D4, Plantago major spag. Peka D6, Sanicula europaea D6, and Thuja occidentalis D6. The initial dosage was 5 drops at intervals of $30 \mathrm{~min}$ which was reduced to $3 \times 20$ drops a day once clinical complaints subsided. Over the entire $10-$ day period, the patients had the possibility to consult their doctors face-to-face or by phone in case of any deterioration in condition.

\section{Results}

Fiftythree patients were enrolled into the trial; in 2 cases, the assessment at $\mathrm{t} 1$ resulted in a prescription of antibiotics due to the deterioration of the clinical picture. Two patients failed to return at $\mathrm{t} 1$, and 2 more did not reappear at $\mathrm{t} 2$. Hence, complete data were collected for 47 patients. The mean age of the participants was 36.3 years $($ standard deviation $=14.43) ; 33(67.3 \%)$ of them were female.

Table 1 shows the results of the outcome criteria. Lower values indicate symptom improvement. The changes in symptom severity (SNOT-16 questionnaire) were highly significant $(\mathrm{p}<0.001)$ showing effect sizes of $\mathrm{d}=1.08$ ( $\mathrm{t} 0$ vs. $\mathrm{t} 1$ ) and $\mathrm{d}=2.42$ ( $\mathrm{t} 0$ vs. $\mathrm{t} 2$ ). CRP values increased slightly between $\mathrm{t} 0$ and $\mathrm{t} 1(\mathrm{~d}=-0.04$, not significant) and then declined towards normalization at $\mathrm{t} 2$ ( $\mathrm{t} 0$ vs. $\mathrm{t} 2$ : $\mathrm{d}=0.60, \mathrm{p}<0.001)$. Also, BSR showed a small increase in the first and in the second hour count (BSRa/BSRb) at $\mathrm{t} 1$ (both $\mathrm{d}=-0.02$, not significant) before dropping at $\mathrm{t} 2$ ( $\mathrm{t} 0$ vs. $\mathrm{t} 2$ : BSRa $\mathrm{d}=0.49, \mathrm{p}<$ 0.001; BSRb d $=0.62, \mathrm{p}<0.001$ ).
At t2, all 47 patients reported no side effects (rating yes/no); also, the GPs reported no side effects for all 47 cases. Moreover, 43 patients (91.5\%) judged the treatment to be 'effective' or 'rather effective' as well as 'satisfying' or 'rather satisfying'. At follow-up 4 weeks after t2, 43 out of 47 patients (91.5\%) reported no further problems in the paranasal sinuses, 3 patients $(6.4 \%)$ reported 'rarely', and 1 patient (2.1\%) 'often' recurring problems.

\section{Discussion}

The present study complements current evidence regarding the treatment of rhinosinusitis with complex homeopathic treatment by the perspective from a natural GP setting with high external validity. Importantly, due to its uncontrolled design, we were not able to draw conclusions regarding the specific efficacy of the treatment in this study. Rather, the objective was to document feasibility and success of this kind of treatment under daily life conditions. Only 2 patients (3.8\%) of our sample fell back on antibiotics. This proportion is consistent with complication rates of $0.5-2 \%$ in upper respiratory tract infections reported in the literature [10]. The remaining patients showed improvements in self-reported symptom severity with large effect sizes of 1.08 after 3 days and 2.42 after 10 days. Simultaneously, the inflammation values CRP and BSR showed a slightly delayed decrease towards non-clinical values. Four weeks after the end of treatment, $91.5 \%$ of the patients completing the treatment did no longer have any problems with their paranasal sinuses. Patients reported no side effects, and 91\% judged the treatment to be 'effective' or rather 'effective' as well as 'satisfying' or 'rather satisfying'.

Various studies allow for an assessment of spontaneous healing rates under placebo or analgetics. The results range from 69\% [11] over $79 \%$ [12] to $75-88 \%$ [13] depending on variables and design. On the other hand, none of these studies report data regarding patients' satisfaction, tolerance, or side effects. Therefore, one can conclude that spontaneous healing rates measured elsewhere were either met or even exceeded in our study, while patients at the 
same time were highly satisfied and showed the best possible tolerance to the treatment. The logical next step for further evaluation of its clinical value would be a proof of effectiveness for RICURA ${ }^{\circledR}$ spag. Peka by a randomized controlled trial.

We conclude that RICURA ${ }^{\circledR}$ spag. Peka is an adequate and suitable treatment option in uncomplicated rhinosinusitis. It constitutes a well tolerable and low-risk medication that may allow for reducing the high number of antibiotics prescriptions which, according to current guidelines, should be avoided anyway.

\section{Acknowledgments}

We would like to thank Tomas Weinert for assistance with the data evaluation and Marius Beyersdorff for his contribution to the manuscript.

\section{Disclosure Statement}

Stefan Schmidt's position in Frankfurt (Oder) during the course of the study was an endowed chair in part funded by Pekana.

\section{References}

1 Monto AS: Viral respiratory infections in the community: Epidemiology, agents, and interventions. Am J Med 1995;99:24S-27S.

2 Deutsche Gesellschaft für Allgemeinmedizin und $\mathrm{Fa}-$ milienmedizin (DEGAM): DEGAM-S3-Leitlinie Nr.10 Rhinosinusitis. Düsseldorf, omikron publishing, 2008, www.degam.de/files/Inhalte/Leitlinien-Inhalte/Dokumente/DEGAM-S3-Leitlinien/LL-10_Langfassung_Rhinosinusitis-005B.pdf.

3 Lemiengre MB, van Driel ML, Merenstein D, Young J, De Sutter AI: Antibiotics for clinically diagnosed acute rhinosinusitis in adults. Cochrane Database Syst Rev 2012; 10:CD006089.

4 Friese K-H, Zabolotnyi DI: Homeopathy in acute rhinosinusitis: a double-blind, placebo controlled study shows the efficiency and tolerability of a homeopathic combination remedy (in German). HNO 2007;55:271277.
5 Zabolotnyi DI, Kneis KC, Richardson A, Rettenberger R, Heger M, et al: Efficacy of a complex homeopathic medication (Sinfrontal) in patients with acute maxillary sinusitis: a prospective, randomized, double-blind, placebo-controlled, multicenter clinical trial. Explore (NY) 2007;3:98-109.

6 Walach H, Loef M: Using a matrix-analytical approach to synthesizing evidence solved incompatibility problem in the hierarchy of evidence. J Clin Epidemiol 2015;68:1251-1260.

7 Schmidt S, Walach H: Making Sense in the Medical System: Plabebo, Biosemiotics and the Pseudomachine; in Goli F (ed): Biosemiotic Medicine. Healing in the World of Meaning. Heidelberg, Springer, 2016, pp 195-215.

8 Garbutt J, Spitznagel E, Piccirillo J: Use of the modified SNOT-16 in primary care patients with clinically diagnosed acute rhinosinusitis. Arch Otolaryngol Neck Surg 2011;137:792-797.
9 Anderson ER, Murphy MP, Weymuller EA Jr: Clinimetric evaluation of the Sinonasal Outcome Test-16. Otolaryngol Head Neck Surg 1999;121:702-707.

10 Fokkens WJ, Lund VJ, Mullol J, Bachert C, Alobid I, et al: European Position Paper on Rhinosinusitis and Nasal Polyps 2012. Rhinol Suppl 2012;(23):1-298.

11 de Ferranti SD, Ioannidis JP, Lau J, Anninger WV, Barza M: Are amoxycillin and folate inhibitors as effective as other antibiotics for acute sinusitis? A metaanalysis. BMJ 1998;317:632-637.

12 Mann W, Pelz K: Ein Beitrag zur bakteriologischen Diagnostik bei der chronischen Sinusitis. Ther 51 1979; 29:8828.

13 Stalman W, van Essen GA, van der Graaf Y, de Melker RA: The end of antibiotic treatment in adults with acute sinusitis-like complaints in general practice? A placebo-controlled double-blind randomized doxycycline trial. Br J Gen Pract 1997;47:794-799. 